\title{
Numerical Evaluation of Pollutants Emissions in a Homogeneous Methane/Air Micro Flame
}

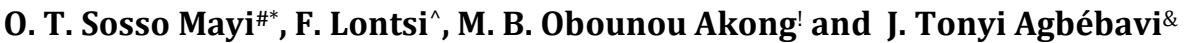 \\ \#Department of Electrical Engineering, ENSET, University of Douala, 1872 Douala, Cameroon \\ ${ }^{\wedge}$ Faculty of Industrial Engineering, EDSFA/UFD SI, University of Douala, 2701 Douala, Cameroon \\ !Department of Physics and Energy, University of Yaoundé I, 337 Yaoundé, Cameroon \\ \&Department of Chemical Engineering, University of Quebec at Trois-Rivières C.P. 500, Trois-Rivières(Québec) G9A 5H7
}

Received 05 May 2018, Accepted 28 June2018, Available online 30 June2018, Vol.8, No.2 (June 2018)

\begin{abstract}
Exhausting pollutant gas in a plug flow micro reactor are identified, described and predicted in this paper. For this, a premixed methane/air micro flame was simulated by a simplified chemical kinetics mechanism with four equations of Jones and Lindstedt. In addition to the Jones and Lindstedt model, one chemical kinetic mechanism with three equations describing the formation of thermal NO was integrated in Comsol 4.2a code, all that equations describing the production process and disappearance of the major chemical species. Simulations in stoichiometric and lean conditions with equivalent ratio $\oint$ equal to 0.9 and 0.7 show that the simulations with Jones and Lindstedt model provide a stable flame with the temperatures of the same order as that obtained with a detailed chemical kinetic mechanism as reported in the literature. Production of carbon dioxide $\left(\mathrm{CO}_{2}\right)$ varies with the richness of the mixture. It is high with $\oint=1$ and in the order of $250 \mathrm{ppm}$, this value remains smaller than the required threshold for breathable air. Carbon monoxide (CO) is not found in the products of combustion due to the high temperatures at the outlet of the microreactor in the three cases.
\end{abstract}

Keywords: Micro reactor, microcombustion, simplified chemical kinetic, pollutant emissions, equivalent ratio

\section{Introduction}

Micro and Nano Portable Generator for energy production (MNPG) based on the combustion of hydrocarbons are reliable alternative for the power supply of equipments such as, laptops, cell phones, robotics, micro rockets, mini planes, drones which could be powered by microreactors (Walther and Ahn, 2011; Martonet al, 2011; Cohen et al, 2005). Combustion is a process used in the MNPG to produce portable energy. However, as their macro counterpart systems the combustion process in MNPG could produce pollutants such as the nitrogen monoxide $\left(\mathrm{NO}_{\mathrm{x}}\right)$ (Aghalayamet al, 2010; Vicanet al, 2002) that is known to be responsible of many health hazards and may represent a significant threat to the environment (Smith, 1993; Hill and Douglas, 2000).

For new energy generation, a complete oxidation of the fuel to $\mathrm{CO}_{2}$ and $\mathrm{H}_{2} \mathrm{O}$ with a minimum amount of any byproducts is desired; unfortunately that never happens due to the combustion chemistry process which generates many species responsible for environmental pollution and human diseases. The rate of fuel supplying MNPG devices is fundamentally less

*Corresponding author's Tel: (237) 6777381 14, ORCID ID: 0000 0002-8151-8287, DOI: https://doi.org/10.14741/ijtt/v.8.2.4 important compared to the quantity of fuel used for larger power devices, since the small size of the devices being considered. It is then easy to infer that, pollutant emissions produced by MNPG are highly weak and without considerable effects on environment if only taking into account a minimal compiled effect. Several researchers concluded that, their $\mathrm{CO}_{2}$ and $\mathrm{H}_{2} \mathrm{O}$ emissions and heat release would be comparable to that of the human being for the mesoscale size and would be significantly less for the microscale ones (Smith, 1993).

Extensive research has been carried out on homogeneous combustion of $\mathrm{CH}_{4}$ and pollutants emissions in macro combustion (Fernandez-Pello, 2002; Hedley et al, 1995; Schmitt et al, 2007; Glaudeet al, 2010; Tsuji et al, 2010; Hollowell, 2011). In micro combustion only few studies are reported concerning the exhaust gases of micro-reactors, Kim et al. (Kim et al, 2005), experimentally studied the pollutants emission of small Swiss roll combustor as heaters; they concluded that as a combustor became smaller $\mathrm{NO}_{\mathrm{x}}$ emission decreased, while the emission of $\mathrm{CO}$ increased. Efingeret al. (Efingeret al, 2005) have reported the characterization and reduction of pollutant emissions from a landfill and digester gas fired microturbine generator. Nascimentoet al. have 
proposed an experimental evaluation and a comparison of the performance and emissions of a regenerative gas microturbine using biodiesel from various sources as fuel (Boiceaet al, 2009; Nascimentoet al, 2007). However the study of the exhaust gases in micro combustion is still weakly investigated in order to highlight the formation process and the amount of different species released.

This study was motivated by the desire to evaluate the pollutant emissions of MNPG since their main objective is to replace batteries in the daily supply of electromechanical devices. A premixed methane flame in a plug flow micro reactor model was investigated. The numerical calculations adopted a coupled set of elliptic equations, with a simplified four steps chemical kinetic mechanism model and thermal NO mechanism with three equations, instead of detailed chemistry in order to reduce the computational time. The major pollutants were evaluated, such as, carbon dioxide, carbon monoxide, nitrogen oxides simultaneously by testing three equivalence ratios $\phi, 0.7,0.9$ or 1 .

The results of this work show that the simplified chemical kinetic mechanism with four global equations can well predict the evolution of major chemical species emissions. The emission of carbon dioxide reaches the concentration of $250 \mathrm{ppm}$, less than the acceptable threshold limit of $450 \mathrm{ppm}$ for a breathable air. In addition, there is no presence of carbon monoxide due to the high reaction temperatures, while the concentration of thermal NO varies with the equivalent ratios. However, due to its tendency to increase, the later needs to be monitored in the lean conditions.

\section{Method}

Premixed mixture methane/air feeds a tubular 2D parallel plate, whose dimensions are: $600 \mu \mathrm{m}$ for the gap and a length of $10000 \mu \mathrm{m}$, as shown in Fig. 1 (a), with alumina walls of $200 \mu \mathrm{m}$ thickness. The input velocity of the reactants is $0.5 \mathrm{~m} / \mathrm{s}$. All calculations were made with COMSOL 4.2a software (COMSOL, 2008).

(a)

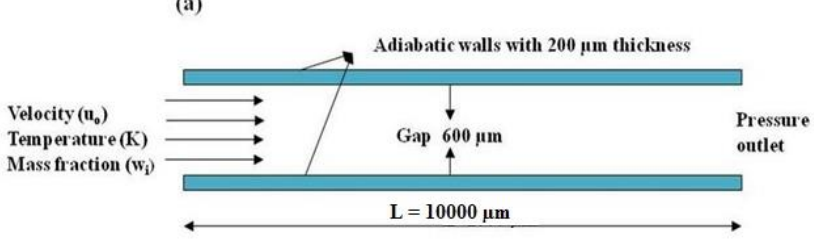

(b)

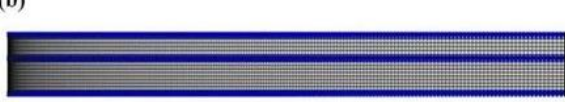

Fig. 1 (a) Schematic of computational domain,(b) Mesh used in the simulations

The origin is fixed at the center of the inlet of the micro reactor, $x$ depicts the axial or downstream distance, while y represents the vertical distance or distance from the centerline of the micro reactor. The assumption is that the component of the swirling velocity is zero, allowing only a symmetrical study by the center of the micro reactor. Only half of the micro reactor will be considered in the calculations, thereby reducing the computational time. Moreover, we consider that there is no Dufour effects (Williams, 1965), no gas radiation (Norton and Vlachos, 2003), no work done by viscous forces and pressure, and steady state conditions are prescribed.

The study of the reactive flow is done in two steps, the first using the reaction engineering module, which sets the selected chemical kinetics mechanism and the analysis of combustion in a reactor model as a plug flow model. It also evaluates all thermodynamic and transport data to achieve combustion in a practical reactor as shown in Fig. 1. The second step is the multiphysical coupling of reaction engineering module with, the transport and concentrated species, heat transfer and laminar flow modules to establish the species transport, heat transfer in gas phase and solid walls, and the flow regime.

\subsection{Reaction Engineering module}

Reaction Engineering Module allows the study of chemical kinetics in different reactor models and sets up the chemical kinetics mechanism which was defined in advance. It calculates the thermodynamic and transport parameters through the chemical and kinetic equations (1), (2). In our study, we have chosen the four step reactions models of Jones and Lindstedt (Jones and Lindstedt, 1988) and five species namely hydrocarbon, oxygen, carbon monoxide, carbon dioxide and water. Its mechanism is reported in the table 1 .

The source term is given by reaction rate equation:

$R_{j}=k^{f} \prod_{i=v}^{Q} c_{i}^{v}$

$k^{f}=A T^{n} \exp \left(-\frac{E_{a}}{R_{g} T}\right)(2)$

In the equations (1), (2), $R_{j}\left(\mathrm{~mol} / \mathrm{m}^{3} / \mathrm{s}\right)$ are the reaction rate of $\mathrm{j}$ species, in our work it's methane, $k^{f}(1 / s)$ is reaction rate constant, $A$ (consistent unit) is the pre-exponential factor, $E_{a}(\mathrm{~J} / \mathrm{mol})$, is the activation energy, $R_{g}(8.314 \mathrm{~J} / \mathrm{mol} / \mathrm{K})$ is the universal gas constant, $T(\mathrm{~K})$ is the temperature, $\mathrm{c}\left(\mathrm{mol} / \mathrm{m}^{3}\right)$ is the molar concentration, $v$ is the concentration exponents or the partial orders of the reaction. The Arrhenius parameters, $\mathrm{A}, \mathrm{n}, \mathrm{E}_{\mathrm{a}}$ are given by (Andersen et al, 2009), their values are defined in the table 1.

\section{2. $\mathrm{NO}_{\mathrm{x}}$ mechanism}

Due to their immense practical relevance, NOx from various types of flames and combustion devices have 
been extensively investigated (Naha and Aggarwal, 2004; Lee et al, 2004). Many researchers in the field of macro combustion have focused on the development of appropriate $\mathrm{NO}_{\mathrm{x}}$ mechanisms for more detailed prediction and investigation of $\mathrm{NO}_{\mathrm{x}}$ emissions from flames. Three mechanisms are generally reported in the literature, namely thermal, fuel and prompt NO mechanisms (Hill and Douglas, 2000; Cho and Chung, 2009). The adopted reaction scheme to describe $\mathrm{NO}_{x}$ contribution in the combustion reactions was chosen in the GRI 3.0 mechanism (Smith et al, 2010). To describe NO formation, prompt and thermal mechanisms were used. The former includes the mechanism through $\mathrm{N}_{2} \mathrm{O}$, in addition to Fenimore mechanism. The reactions leading to $\mathrm{NO}_{2}$ formation are also included (Nishiokaet al, 1994).

Thermal NO (Zeldovich) is the one obtained by the following three mechanisms:

$\mathrm{O}+\mathrm{N}_{2} \leftrightarrow \mathrm{NO}+\mathrm{N}(3)$

$\mathrm{N}+\mathrm{O}_{2} \leftrightarrow \mathrm{NO}+\mathrm{O}(4)$

$\mathrm{N}+\mathrm{OH} \leftrightarrow \mathrm{NO}+\mathrm{H}(5)$

The thermal NO is the result of the oxidation of molecular nitrogen in the post-flame region. Reaction (3) is the step limiting of this mechanism. This reaction has high activation energy. It will be fast at high temperatures and will take place in the flame front. That is why it is predominant in the combustion chamber at high temperature ( $>1500 \mathrm{~K}$ ). Its formation is related to the concentration of oxygen and the duration of flow of air in the reaction zone.

Fuel mechanism $\left(\mathrm{N}_{2} \mathrm{O}\right)$ is the summation of its production through the following three reactions in the full mechanism calculation:

$\mathrm{N}_{2} \mathrm{O}+\mathrm{O} \leftrightarrow 2 \mathrm{NO}(6)$

$\mathrm{N}_{2} \mathrm{O}+\mathrm{H} \leftrightarrow \mathrm{NH}+\mathrm{NO}(7)$

$\mathrm{N}_{2} \mathrm{O}+\mathrm{CO} \leftrightarrow \mathrm{NCO}+\mathrm{NO}(8)$

The NO fuel mechanism is due to the oxidation of organic nitrogen in the fuel components and oxygen at temperatures higher than $1300 \mathrm{~K}$ (Yang and Blasiak, 2005). The carbon-nitrogen bond has a much lower binding energy than in $\mathrm{N}_{2}$ link. This type of training will be easier and faster at "low temperature" than the mechanism of thermal NO. $\mathrm{N}_{2} \mathrm{O}$ mechanism is the summation of its production through the following five reactions in the full mechanism calculation:

$\mathrm{NO}_{2}+\mathrm{OH} \leftrightarrow \mathrm{HO}_{2}+\mathrm{NO}(9)$
$\mathrm{NO}_{2}+\mathrm{M} \leftrightarrow \mathrm{O}+\mathrm{M}+\mathrm{NO}(10)$

$\mathrm{NO}_{2}+\mathrm{O} \leftrightarrow \mathrm{O}_{2}+\mathrm{NO}(11)$

$\mathrm{NO}_{2}+\mathrm{H} \leftrightarrow \mathrm{OH}+\mathrm{NO}(12)$

$\mathrm{NO}_{2}+\mathrm{CN} \leftrightarrow \mathrm{NCO}+\mathrm{NO}$

Prompt NO (Fenimore) mechanism is the one obtained by the full mechanism calculation minus the summation of the above three mechanisms:

$\mathrm{CH}+\mathrm{N}_{2} \leftrightarrow \mathrm{HCN}+\mathrm{N}(14)$

$\mathrm{C}+\mathrm{N}_{2} \leftrightarrow \mathrm{CN}+\mathrm{N}(15)$

$\mathrm{HCN}+\mathrm{O} \leftrightarrow \mathrm{NCO}+\mathrm{H}$

$\mathrm{NCO}+\mathrm{H} \leftrightarrow \mathrm{NH}+\mathrm{CO}(17)$

$\mathrm{NH}+\mathrm{H} \leftrightarrow \mathrm{N}+\mathrm{H}_{2}(18)$

$\mathrm{N}+\mathrm{OH} \leftrightarrow \mathrm{NO}+\mathrm{H}(19)$

Prompt NO is formed by the reaction of the free oxygen in excess air. It is produced rapidly in the flame zone, long before NO is formed by the thermal mechanism (Hill and Douglas, 2000).

The general scheme is such that the species HCN and $\mathrm{CN}$ are first formed by the hydrocarbon radicals. Unlike the mechanism of thermal NO, prompt NO occurred in rich medium at relatively low temperatures (>1000 K) (Hill and Douglas, 2000).

Using these classifications the portion of each mechanism can be evaluated in the numerical calculation. This is one advantage of numerical study over experimental study because the experimental result only showed global NO emission (Cho and Chung, 2009). Nevertheless, in the frame of our study, only the thermal NO mechanism will be evaluated. Our study will focus on the thermal NOx emission because fuel NO mechanism has a low probability to occur when the temperature is high, which is our case in the premixed methane micro flame studied. On the other hand, prompt NO is favoured in the rich condition whereas in the case of MNPG the stable combustion is generally in the lean condition. Further, Lee et al. showed that thermal NO route was dominant at a low velocity gradient and the prompt NO route was dominant at a high velocity gradient (Lee et al, 2004) whereasKaisare and Vlachos demonstrated that, methane micro flames are stable with velocity in the range of $0.35-0.8 \mathrm{~m} / \mathrm{s}$ (Kaisare and Vlachos, 2007). Reaction rate parameters for thermal NO mechanism are reported in table 2 . 
Table 1: Jones and Lindstedt global four step mechanism with the kinetic Rate Data (units in $\mathrm{cm}, \mathrm{s}, \mathrm{cal}, \mathrm{mol}$ ), (Smith et al, 2000)

\begin{tabular}{cccccc}
\hline No & Reactions & $\mathrm{A}$ & $\mathrm{n}$ & $\mathrm{E}_{\mathrm{a}}$ & Reaction orders \\
\hline JL1 & $\mathrm{CH}_{4}+0.5 \mathrm{O}_{2} \rightarrow \mathrm{CO}+2 \mathrm{H}_{2}$ & $7.82 . \mathrm{E}^{+13}$ & 0 & $30 . \mathrm{E}^{+3}$ & {$\left[\mathrm{CH}_{4}\right]^{\wedge} \cdot .5 \cdot\left[\mathrm{O}_{2}\right]^{\wedge 1.25}$} \\
JL2 & $\mathrm{CH}_{4}+\mathrm{H}_{2} \mathrm{O} \rightarrow \mathrm{CO}+3 \mathrm{H}_{2}$ & $0.30 . \mathrm{E}^{+12}$ & 0 & $30 . \mathrm{E}^{+3}$ & {$\left[\mathrm{CH}_{4}\right] \cdot\left[\mathrm{H}_{2} \mathrm{O}\right]$} \\
$\mathrm{JL} 3 \mathrm{~b}$ & $\mathrm{H}_{2}+0.5 \mathrm{O}_{2} \rightarrow \mathrm{H}_{2} \mathrm{O}$ & $1.21 . \mathrm{E}^{+18}$ & -1 & $40 . \mathrm{E}^{+3}$ & {$\left[\mathrm{H}_{2}\right]^{\wedge} 0.25 \cdot\left[\mathrm{O}_{2}\right]^{\wedge 1.5}$} \\
$\mathrm{JL} 4$ & $\mathrm{CO}+\mathrm{H}_{2} \mathrm{O} \rightarrow \mathrm{CO}_{2}+\mathrm{H}_{2}$ & $2.75 . \mathrm{E}^{+12}$ & 0 & $20 . \mathrm{E}^{+3}$ & {$[\mathrm{CO}] \cdot\left[\mathrm{H}_{2} \mathrm{O}\right]$} \\
\hline
\end{tabular}

Table 2: Reaction rate parameters for extended Zeldovich mechanism (Kaisare and Vlachos, 2007)

\begin{tabular}{cccc}
\hline Reaction expression & $\begin{array}{c}\mathrm{A} \\
\left(\mathrm{cm}^{3} \mathrm{gmol}^{-1} \mathrm{~s}^{-1} \mathrm{~K}^{-1}\right)\end{array}$ & $\mathrm{n}$ & $\mathrm{E}_{\mathrm{a}}$ \\
\hline $\mathrm{O}+\mathrm{N}_{2} \leftrightarrow \mathrm{NO}+\mathrm{N}$ & $1.36 . \mathrm{E}^{+14}$ & 0 & 315,900 \\
$\mathrm{~N}+\mathrm{O}_{2} \leftrightarrow \mathrm{NO}+\mathrm{O}$ & $6.40 . \mathrm{E}^{+9}$ & 1 & 26,300 \\
$\mathrm{~N}+\mathrm{OH} \leftrightarrow \mathrm{NO}+\mathrm{H}$ & $3.28 . \mathrm{E}^{+13}$ & 0 & No temperature dependence \\
\hline
\end{tabular}

\subsection{Numerical Model}

- Since the flow regime is laminar with one Reynolds number less than 2000 ( $\operatorname{Re}=74.83$ ), we choose the Laminar flow module to describe the flow of fluid along the axial displacement of the reactor. It is defined by the equations of continuity and momentum (20) and (21).

- The Heat transfer module in the fluid expresses the heat transfer through the fluid along the axial displacement of the reactor and walls. It is defined by the equations of energy (22), (23) and (26).

- Transport and Concentrated species Module, describes the transport of species in determining the transport coefficients. It is defined by the equation of conservation of species transport (24), (25), (27), (28) and (29).

The 2D governing equations are defined as follows:

$$
\begin{aligned}
& \nabla \cdot(\rho u)=0(20) \\
& \rho(u \cdot \nabla) u=\nabla \cdot\left[p I+\rho\left(\nabla u+(\nabla u)^{T}-\frac{2}{3} \mu(u \cdot \nabla) I\right)\right]+F(21) \\
& \rho C_{p} u \cdot \nabla T=\nabla \cdot(k \nabla T)+Q(22) \\
& \nabla \cdot(k \nabla T)=0(23) \\
& \nabla \cdot j_{j}+\rho(u \cdot \nabla) \omega_{j}=R_{j}(24) \\
& j_{j}=-\left(\rho D_{j}^{m} \nabla \omega_{i}+\rho \omega_{i} D_{j}^{m} \frac{\nabla M_{n}}{M_{n}}+D_{j}^{T} \frac{\nabla T}{T}\right)(25) \\
& Q=-H_{s r} R_{j}(26) \\
& D_{j}^{m}=\frac{1-\omega_{i}}{\sum_{k \neq i} \frac{x_{k}}{D_{j k}}} \\
& M_{n}=\left(\sum_{i} \frac{\omega_{j}}{M_{j}}\right)
\end{aligned}
$$

$\rho=\frac{\mathrm{P}}{\mathrm{RT}} \mathrm{M}_{\mathrm{n}}$

In these equations, $\rho\left(\mathrm{kg} / \mathrm{m}^{3}\right)$ is the density of the reactants, $\mu$ the dynamic viscosity (Pa.s), $\mathrm{k}(\mathrm{W} / \mathrm{mK})$ the thermal conductivity of the mixture, $\mathrm{k}_{\mathrm{w}}(\mathrm{W} / \mathrm{mK})$ the thermal conductivity of the wall, $\mathrm{C}_{\mathrm{p}}(\mathrm{J} / \mathrm{kgK})$ the specific heat, $\mathrm{M}_{\mathrm{j}}(\mathrm{kg} / \mathrm{mol})$ is the molar mass of each species, $M_{n}(\mathrm{~kg} / \mathrm{mol})$ is the molar mass of the mixture, $\mathrm{p}(\mathrm{Pa})$ is the pressure. $\mathrm{H}_{\mathrm{sr}}(\mathrm{J} / \mathrm{mol})$ is the enthalpy of formation of species, the mass fraction $w_{i}$ and $D_{j k}$ $\left(\mathrm{m}^{2} / \mathrm{s}\right)$ is the multi component Maxwell-Stefan diffusivity.

The 2D governing equations are discretized by the finite element method and solved by Comsol $4.2 \mathrm{a}$ (COMSOL, 2008). The equations are solved implicitly with a separate 2D solver using a method of relaxation, while computing the first equations of momentum and the continuity, followed by an update of the pressure and mass flow, energy and species transport equations. The iterations are controlled and monitored until a convergent solution is obtained. The convergence criteria for residuals are $1 \times 10^{-3}$ for all equations.

The gas density is calculated using the ideal gas law. The gas viscosity, specific heat and thermal conductivity are based on the average of the mass fraction of all species.

The boundary conditions are such that we have, at the inlet a linear velocity of $\mathrm{u}_{0}=0.5 \mathrm{~m} / \mathrm{s}$, the choice of this velocity being justified by the fact that it is closed to the combustion speed of methane $(0.40 \mathrm{~m} / \mathrm{s})$, in addition it is one of the parameters of the flame stability in a micro reactor (Schmitt et al, 2007). The uniform inlet temperature is $300 \mathrm{~K}$ in the center of the micro reactor, the mass fraction $\mathrm{w}_{-} \mathrm{CH}_{4}=0.055$, the equivalence ratio of the fuel change with the case studied between $1,0.9,0.7$, from these conditions, the oxidiser will be raised. The choice of composition of the mixture is inferred by the fact that quenching distance for a stoichiometric composition is lower than that of lean mixtures (Gutkowski, 2013; Chou et al, 2009), noslip boundary condition is imposed at the solid-fluid 
interface $\mathrm{u}=0 \mathrm{~m} / \mathrm{s}$, the heat flux is calculated from Fourier's law, the continuity of the temperature and the heat flux create the link between the gas and solid phase. In our simulations, a non-regular mesh is used with more nodes concentrated at the inlet reactor, around the reaction zone. The computations were performed with 4320 nodes (Fig. 1(b)). A high temperature $(1800 \mathrm{~K})$ is imposed on the entire computational domain (both gases and solid) as an initial guess for the numerical iteration. It is important to use a temperature high enough to 'ignite' the mixture. Lower temperature may fail ignition for some cases. The physical and boundary conditions summarized in this section are applied to all cases in this study.

\section{Results and discussion}

\subsection{Structure of microflame}

The study of the pollutants emitted from a rectangular micro reactor was motivated by the fact that this reactor geometry is one of the oldest and simplest MPG studied by the researchers (Norton and Vlachos, 2003; Maruta, 2011; Sosso et al, 2014). Furthermore a series of MEMS-based power generators with rectangular configuration have been prototyped (Chou et al, 2011), so its probability to be used in a real micro reactor is higher than others. A premixed methane/air micro flame was simulated using a simplified chemical kinetics mechanism with four overall equations in the cases of stoichiometric combustion $(\phi=1)$ and lean combustion with equivalence ratio $\phi=0.9$ and $\phi=0.7$. The mechanism of thermal NO consisting of three equations has been associated with Jones and Lindstedt mechanism. Figure 2 ((a), (b) and (c)), presents the results of simulations of different flames obtained under these conditions.

We observe that the simulated flames are anchored in the entrance of microreactor. They all have the same convex shape and describe three distinct zones: the preheating zone is established on a thin distance, the reaction zone with two subzones, ignition and inflammation zone as described by Leach et al. (Leach et al, 2006) varies according to different parameters and which enables recirculation of the heat required for preheating the cold reactant if not taken in account the ignition mode. Finally the last zone is the rest of the micro reactor which allows the exhaust of the combustion products. However it should be noted that the analysis of the flame structure shows that the richness of the mixture influences intensively the position of the micro flame. In the stoichiometric operation, the fluid that enters at the room temperature is preheated by the action of the warmed walls through the heat recirculation, the premixture is ignited and the flame is formed almost at the entrance of micro reactor. In lean conditions the flame is deflected towards the middle of the micro reactor. With an equivalence ratio equal to 0.9 , the flame is still anchored at the entrance of the micro reactor, while when the richness of the mixture is 0.7 , the flame location moves significantly downstream, creating a cold accumulating fluid at the entrance of the microreactor. The change of the flame location has been already reported in several articles and has been justified by the action of the input velocity of the reactants. It is well known that, when the input velocity of the reactants is greater than the combustion speed, the flame is blown and shaped much further from the entry of the micro reactor, but if the velocity of the reactants is less than that of combustion, the flame shape is very closed to the entry of the micro reactor.
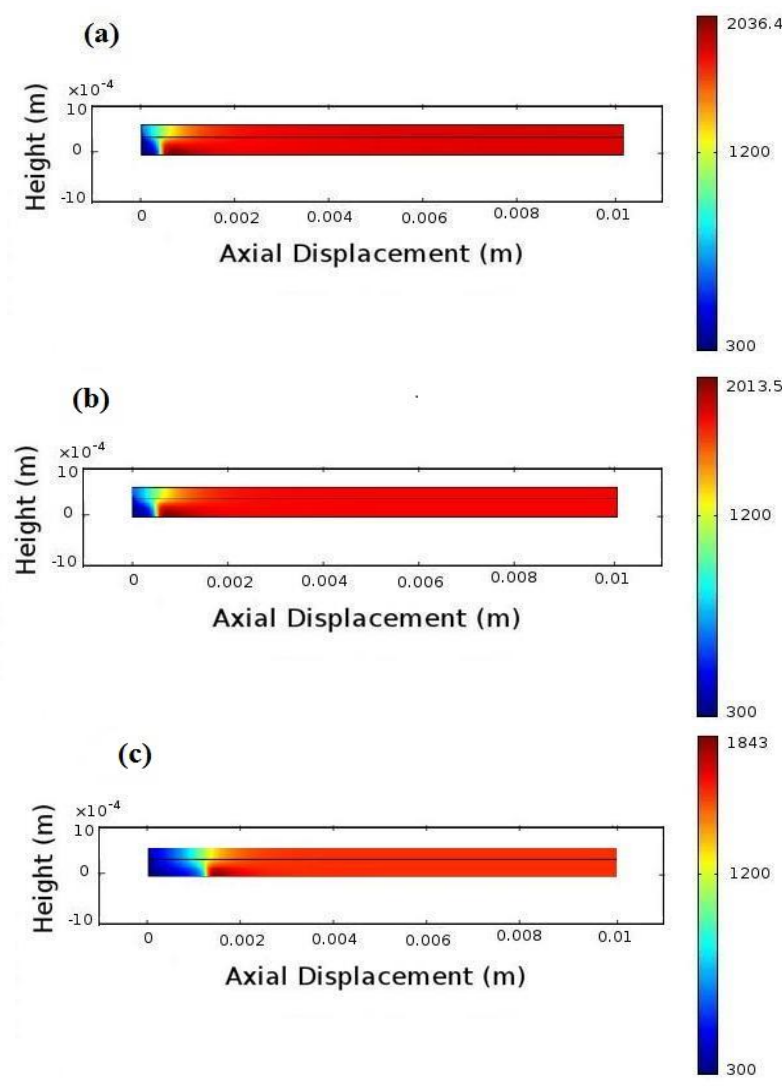

Fig. 2: Results of flame simulation giving heat distribution within the microreactor with different equivalent ratio: a) $\phi=1$, b) $\phi=0.9$, c) $\phi=0.7$

With the results obtained we can highlight that, with the change of equivalence ratio to stoichiometric at lean conditions in the same conditions, the flames are moved. We can explain it by the fact that, the flame speed is function of ignition temperature, which means that, if the ignition temperature changes, consequently the flame speed will change and somewhere the flame location would be affected and even put off.

Figure 3 (a) shows the profile of the temperature at the center of the microreactor under the three conditions mentioned above ( $0.7 \leq \phi \leq 1)$, in the case of the stoichiometric mixture, the fluid enters at $300 \mathrm{~K}$ and reaches the ignition temperature at $\mathrm{x}=0.0005 \mathrm{~m}$, when $\mathrm{x}=0.00085 \mathrm{~m}$ the combustion temperature of $2086 \mathrm{~K}$ is reached, this temperature is lesser than the adiabatic temperature equal to $2240 \mathrm{~K}$, the 
temperature begins to drop to $\mathrm{x}=0.00125 \mathrm{~m}$ to become constant at $\mathrm{x}=0.002 \mathrm{~m}$ and maintain throughout the rest of the micro reactor at $1800 \mathrm{~K}$. Similarly, in the lean conditions, the temperature profile shows that for the case of $\phi=0.9$, the temperature combustion is equal to $2013 \mathrm{~K}$ while the adiabatic equilibrium temperature is closed to $2140 \mathrm{~K}$. However, in the case of $\phi=0.7$, the ignition temperature of $1250 \mathrm{~K}$ is reached at $\mathrm{x}=0.0015 \mathrm{~m}$ and the combustion temperature get to $1843 \mathrm{~K}$ and closed of adiabatic temperature is obtained at $\mathrm{x}=0.00175 \mathrm{~m}$, it decreases to $1550 \mathrm{~K}$ at $\mathrm{x}=0.0025 \mathrm{~m}$, and remains constant along the remainder of the micro reactor. The micro flame temperatures simulated for the two first cases are underestimated. That underestimation can be explained by the fact that the heat produced is distributed to the walls and combustion products, in addition the cracking process of chemical species is endothermic. Several researchers have shown that the used of one step chemical kinetic mechanism lead to overestimated microcombustion temperature (Norton and Vlachos, 2003; Sosso et al, 2014) and justified it by the heat sinks action of microreactor walls on the one hand, on the other hand by the fact that the combustion in this case is particularly abrupt. While the Jones and Lindstedt mechanism is the reduced chemical kinetic mechanism, the number of chemical species involved is much more numerous than those in one step chemical kinetic model, about ten species $\mathrm{CH}_{4}, \mathrm{O}_{2}, \mathrm{CO}, \mathrm{CO}_{2}, \mathrm{H}_{2} \mathrm{O}$, $\mathrm{N}_{2}, \mathrm{O}, \mathrm{N}, \mathrm{NO}, \mathrm{OH}$ are generated or reduced. The magnitude of the temperature obtained is similar to that obtained with microflames simulated using a detailed chemical kinetics with 16 species and 25 reversible reactions developed by Smooke and Giovangigli $(\sim 1800 \mathrm{~K})$ as reported in the literature ( $\mathrm{Li}$ et al, 2009). Somewhere as Jones and Lindstedt mechanism described the chemical species dissociation, in comparison to the overall one step kinetic mechanism, it's logical that the combustion temperatures obtained are less than the magnitude of adiabatic temperature. Nevertheless in the case of equivalence ratio equal to 0.7 , the temperature is closed to adiabatic temperature, we think that the accumulation of reactant at the entrance of the reactor allows the reaction of an important quantity of mixture and then a production of much heat.

Also it is possible in these cases to determine the thickness of the simulated flames proposed by Sung and Law formula (Law and Sung, 2000).

$\delta_{r}=\frac{T_{f}-T_{0}}{\left(\frac{\partial T}{\partial x}\right)_{\max }}(31)$

In the case of a stoichiometric mixture $\delta_{r}=3,6 \mathrm{~mm}$, in the other two conditions , $\delta_{r}=3,67 \mathrm{~mm}$ and $\delta_{r}=3.9 \mathrm{~mm}$ respectively with $\phi=0.9$ and $=0.7$. These values of the thickness of the flame is greater than seven to nine times that of the thickness of a free flame methane jet estimated to $0.42 \mathrm{~mm}$ (Walther and Ahn, 2011). These thicknesses show the effect of the warmed walls on the micro combustion process, which permit the preheating of cold entrance mixture and then the broadening of the reaction zone.
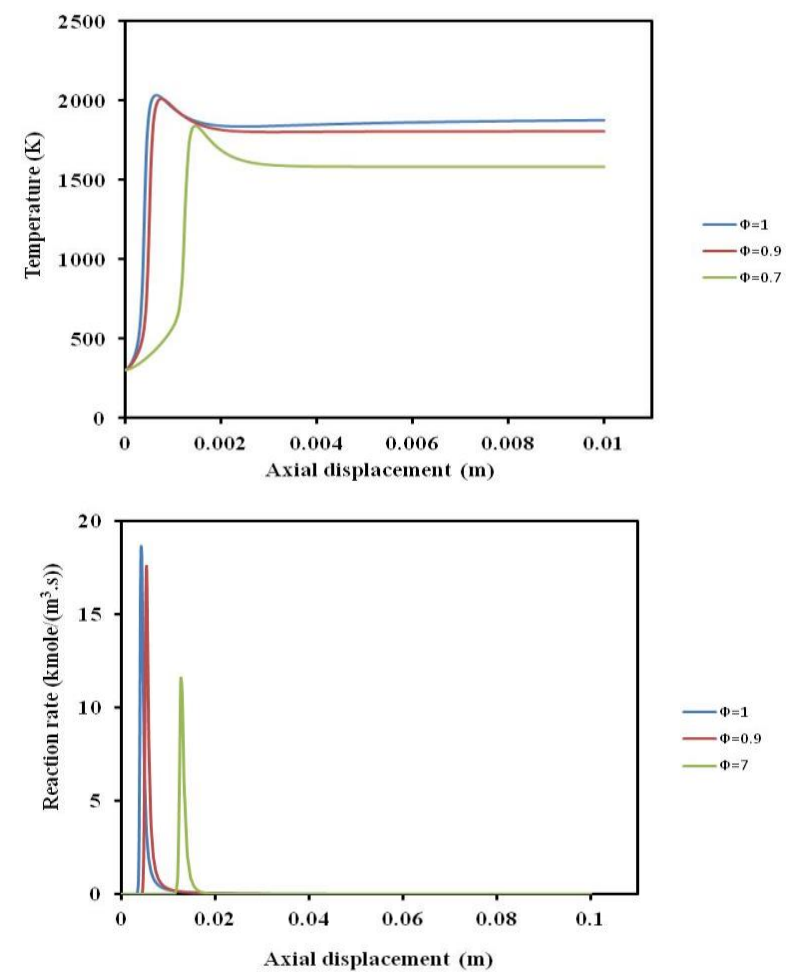

Fig. 3 a) Temperature profile along with the axial displacement of microreactor, b) reaction rate profile along with the axial displacement of microreactor

Figure 3 ( b) shows the evolution of the reaction rate, we can realize that the amount of fuel that reacts in the case of a stoichiometric mixture is of $18 \mathrm{kmol} /\left(\mathrm{m}^{3} . \mathrm{s}\right)$ and $17 \mathrm{kmol} /\left(\mathrm{m}^{3} . \mathrm{s}\right)$ in the case of a lean mixture when $\phi=0.9$. It is therefore understandable why the temperatures obtained in both cases are high and consequently think that all the fuel has reacted. In the case of equivalence ratio equal to $\phi=0.7$, the level of the reaction rate is much lower and is equal to 12 $\mathrm{kmole} /\left(\mathrm{m}^{3} . \mathrm{s}\right)$, which may suggest that all the fuel is not burned, which is explained by the fact that a larger amount of cold reagent enters the reaction zone without any time to benefit from the effect of preheating from the heat recirculated through the inlet walls.

The results clearly show that the reduced Jones and Lindstedt chemical kinetics four equations can be used in the case of the simulation of the combustion in the MPG and can reproduce flame speeds, flame thicknesses and species profiles. This leads to the same conclusion as Ennettaet al. who showed that this chemical kinetics mechanism can describe flame behavior within a microreactor with results closed to those obtained with detailed chemical kinetics mechanism (Leach, 2006).

\subsection{Pollutants production analysis}

Figures 4(a), (b) and (c) show the profiles of the production and disappearance of major species during combustion in the micro reactor in stoichiometric and 
lean conditions. Figure 4 (a) shows that the mass fraction of the oxygen is greatly reduced after the reaction zone and almost disappear in the reactor outlet, while methane disappears soon after combustion. The mass fraction of water and production of carbon dioxide $\left(\mathrm{CO}_{2}\right.$ and $\left.\mathrm{H}_{2} \mathrm{O}\right)$ is important and we can distinguish the production of the thermal NO in inset only because its production is lower than others species. The curve describing the carbon monoxide (CO) is such that, it is formed in the reaction zone but will disappear shortly after, and will not appear in the flue gases.

In Figure 4 (b), it is possible to establish the same finding as above, the equivalence ratio of the mixture is then 0.9 , nevertheless there is the presence of excess oxygen at the output of the micro reactor and a slight decrease in the production of water and carbon dioxide.

Figure 4 (c) shows the formation of combustion products and the disappearance of the reactants in a lean mixture with a equivalence ratio of 0.7 , the accumulation of fluid at the inlet of the micro reactor as explained more above allows us to understand that even if all the fuel burns, there's a strong production of carbon monoxide compared to the first two conditions, in addition, the excess of oxygen at the exit of micro reactor is much larger and in the same order as that of water $\mathrm{w}_{-} \mathrm{O} 2=\mathrm{w}_{-} \mathrm{H} 2 \mathrm{O}=0.08$. The carbon dioxide produced is smaller than that obtained in the other two conditions. As in a lean and stoichiometric mixture, the production of thermal NO as zoomed on the graph is largely low compared to that of all other species. Special analysis of $\mathrm{CO}_{2}, \mathrm{CO}$ and $\mathrm{NO}$ representing potentially harmful pollutants for both the environment and for health will be done in the next sections.
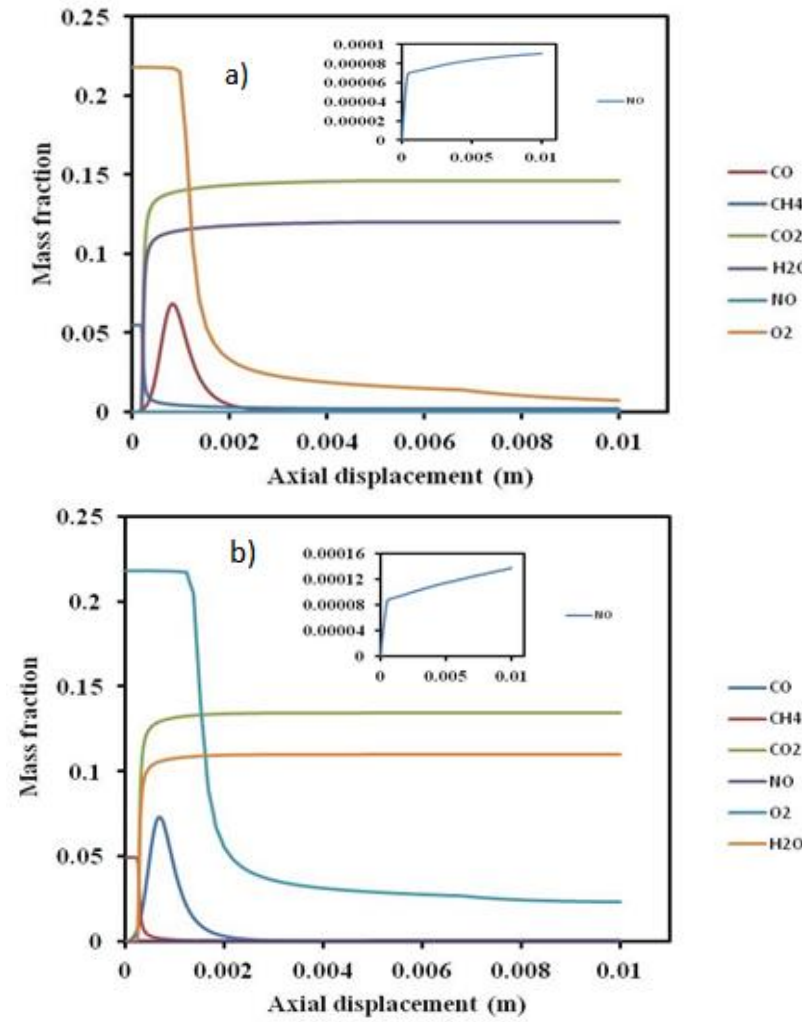

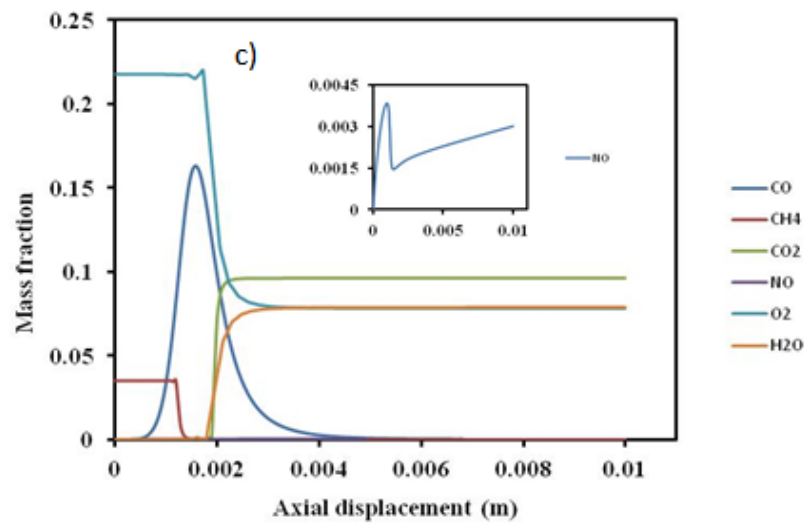

Fig.4: Production and disappearance profile of major chemical species along with the axial displacement of microreactorwith a) $\phi=1$, b) $\phi=0.9$, c) $\phi=0.7$

\section{Carbon dioxide emission}

C02, is an inevitably gas present in the combustion products, even if it is a greenhouse gas; $\mathrm{CO}_{2}$ is produced by both humans and by several other devices. A human being rejects average amount of $\mathrm{CO}_{2}$ estimated at $0.02 \mathrm{cfm}$, and in a work environment or housing, air having an amount of $450 \mathrm{ppm}$ is considered safe (Hoskins, 2003). Several researchers have previously indicated that the MPG given their low fuel consumption would have a less production of carbon dioxide than the human being.

Our study shows that $\mathrm{CO}_{2}$ is indeed produced, but at a concentration lower than the threshold limit of what is required for a breathable air. Figure 5 shows the evolution of the production of carbon dioxide as function of the equivalence ratio. It can be observed that the production of $\mathrm{CO}_{2}$ decreases with the richness of the mixture. This is explained by the fact that carbon dioxide is a good indication of combustion.

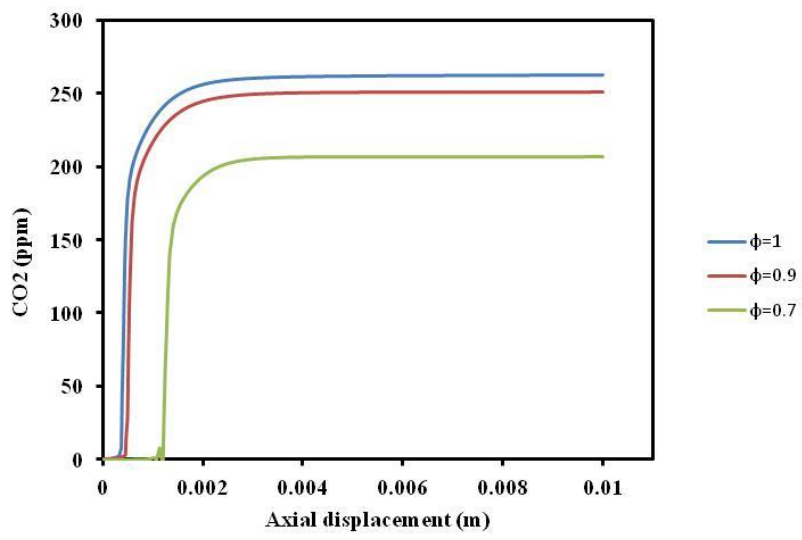

Fig. 5 Carbon dioxide production profile along with the axial displacement of microreactor for:a) $\phi=1$, b) $\phi=0.9$, c) $\phi=0.7$

An important point to take in account from figure 5 shows that the maximum $\mathrm{CO}_{2}$ concentration is 253 ppm , $248 \mathrm{ppm}$ and $200 \mathrm{ppm}$ respectively for $\phi=1$, $\phi=0.9$ and $\phi=0.7$. It is therefore possible to infer that 
the production of $\mathrm{CO}_{2}$ in the case of MPG is acceptable for breathing and would not constitute a hazard, at least in the case of the reactor model studied. But the hazard also depends on the type of exposure.

\section{Carbon monoxide emission}

Carbon monoxide is a dangerous gas to health, because it attacks the respiratory system and can even be fatal in low doses. It would require a concentration of less than $1 \mathrm{ppm}$ of $\mathrm{CO}$ in air for safe respiration (Vlachos et al, 1994). It is therefore important in the design of a combustion device to be interested in its presence in the combustion products released by such a system. Figure 6 shows the profile of the carbon monoxide (CO) produced in a rectangular configuration microreactor plug flow model. Here, its presence is due to the dissociation of the chemical species. Once the reactants entered the reactor, the mixture temperature increases, the species begin their transformation, carbon monoxide appears and increases progressively in the same direction as the temperature of the reactants, and reaches its maximum when the combustion temperature is reached. Vlachos et al. noted that in the case of combustion where the walls play an important role, the mixture is converted substantially to $\mathrm{CO}_{2}$ near the walls after the ignition of the reactants and even at high temperature, only $75 \%$ of $\mathrm{CO}$ is converted in the main reaction mixture (Vlachos et al, 1994). In the case of the stoichiometric combustion $\mathrm{CO}$ concentration reaches about $68 \mathrm{ppm}$, though it falls slightly to $63 \mathrm{ppm}$ when the equivalent ratio of the reaction mixture is 0.9 .

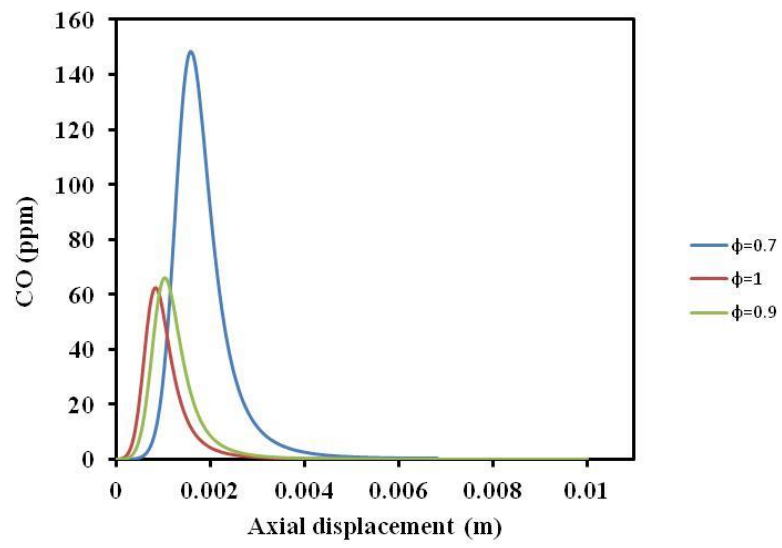

Fig. 6 Carbon monoxide production profile along with the axial displacement of microreactor for:a) $\phi=1$, b) $\phi=0.9$, c) $\phi=0.7$

But a very important increase of $\mathrm{CO}$ appears when the equivalent ratio is 0.7 , till a peak of $148 \mathrm{ppm}$. This significant change when $\phi=0.7$ in the concentration of $\mathrm{CO}$ in the combustion process is due to the large amount of cold fluid which is found in the reaction zone when the temperature of the reagents develops. In all three cases, the CO disappears completely and is transformed to $\mathrm{CO}_{2}$ when the combustion temperature drops to stabilize to the temperature of the flue gas These temperatures, respectively in the order of 1800 $\mathrm{K}, 1750 \mathrm{~K}$ and $1550 \mathrm{~K}$ are still large enough to burn the carbon and this explains the lack of $\mathrm{CO}$ in the combustion products released by this microreactor model.

It is worth to mention that one of the characteristics of MPG is to have high flue gas temperatures and more fundamentally they always operate in lean conditions providing a barrier to the presence, even in trace, of carbon monoxide in the combustion products.

\section{Nitric oxide emission}

The presence of nitric oxide is evaluated using two parameters, the concentration and the Emission Index of the thermal NO, known as EINO. Figure 7 represents the profile of NO production along the axis of the microreactor as function of the equivalence ratio. The production is relatively high for $\phi=0.7$. In the three richness conditions, the NO concentration varies, increases along the reactor, reaches its values 3.6, 4.4 and $11.8 \mathrm{ppm}$ at the burning, respectively for the equivalence ratios of $\phi=1, \phi=0.9$ and $\phi=0.7$. Once the temperature drops, the thermal NO also drops drastically to the two thirds of its production. It rises slightly to 0.18 and $0.2 \mathrm{ppm}$ even when the temperature of the combustion products is constant for an equivalence ratio of 1 and 0.9 . However in the case of lean condition where $\phi=0.7$, the increase of the concentration of $\mathrm{NO}$ is worrying as it reaches the value of $0.8 \mathrm{ppm}$, despite a lower flue gas temperature compared to the cases above. However it's important to highlight that few year before in an experimental study, Nam Il Kim et al. showed that $\mathrm{NO}_{\mathrm{x}}$ production decreases with equivalence ratio within a Swiss-roll combustor (Kim et al, 2005), they find $\mathrm{NO}_{\mathrm{x}}$ emission was less than about $100 \mathrm{ppm}$ at an equivalence ratio 0.9 , and less than $60 \mathrm{ppm}$ at an equivalence ratio 0.7 .

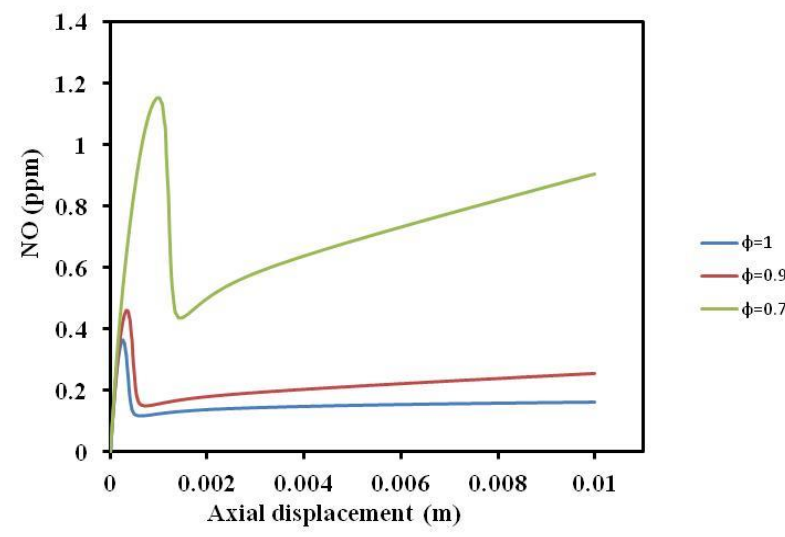

Fig. 7 Nitrogen monoxide production profile along with the axial displacement of microreactor for: a) $\phi=1$, b) $\phi=0.9$, c) $\phi=0.7$ 


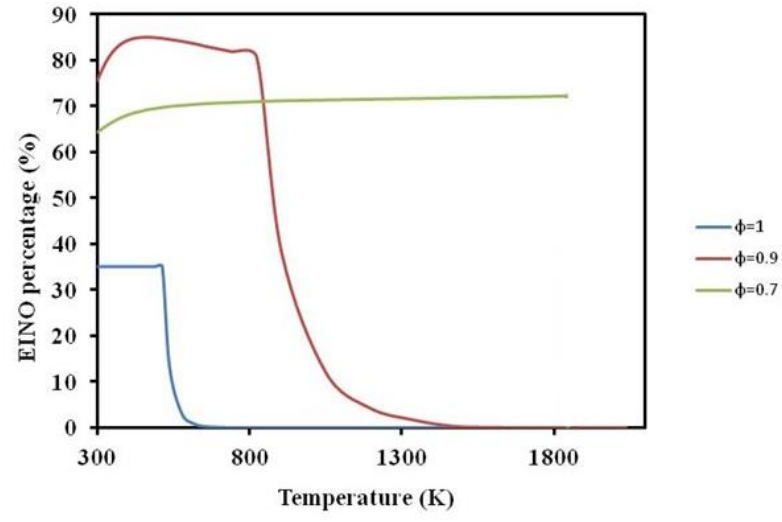

Fig. 8 Emission index profile as function of micro reactor temperature with different equivalent ratio: a) $\phi=1$, b) $\phi=0.9$, c) $\phi=0.7$

Their results seem to be contrary of what we find; nevertheless it can be explained by the form of combustor which plays a key role for the emission of burned mixture. In addition, the results given by Nam Il Kim et al. have to be considered as an average of production of prompt, thermal and fuel NO, while in this case only the thermal NO is significant.

The production of thermal NO is also analysed by its emission index (EINO) as calculated by Takeno and Nishioka (Takeno and Nishioka, 1993), as:

EINO $=\frac{\int_{-\mathrm{L}}^{\mathrm{L}} \dot{\omega}_{\mathrm{NO}} \mathrm{W}_{\mathrm{NO}} \mathrm{dx}}{-\int_{-\mathrm{L}}^{\mathrm{L}} \dot{\omega}_{\mathrm{CH} 4} \mathrm{~W}_{\mathrm{CH} 4} \mathrm{dx}}$

EI is the production rate of $\mathrm{NO}$ and $\dot{\omega}_{\mathrm{CH} 4}$ is the consumption rates of methane. $\mathrm{w}_{-} \mathrm{NO}$ and $\mathrm{w}_{-} \mathrm{CH} 4$ respectively represent the molar mass of $\mathrm{NO}$ and $\mathrm{CH}_{4}$.

In this case of Figure 8 (b), the EINO is a function of the temperature in the microreactor. Cho and Chung show that the EINO index monotonically increases with increasing phi form 0.5 to 1 (Cho and Chung, 2009) in our study the EINO index was studied in comparison with the temperature evolution. We notice that the EINO index greatly decrease with the increase of the temperature in the both case of equivalence ratio equal to 0.9 and 1 , while in the case of equivalence ratio equal to 0.7 the EINO remains quite constant. At low temperature, the production of NO is important in all three cases $(\phi=1, \phi=0.9, \phi=0.7$ ) respectively 35\%, $65 \%$ and $75 \%$. The reaction of excess oxygen in the mixture with the nitrogen in the presence of the temperature above $1400 \mathrm{~K}$ is responsible for this increase at very lean mixture. Therefore, it becomes a challenge to find a compromise between operating the MPGs at lean condition and minimizing simultaneously the NO production.

This peculiar behavior of EINO index may result the position of the flame, because the NO is almost constant before the flame reach to its highest level, once the temperature begins to decrease, the NO production also decreases.

\section{Conclusion}

The analysis of the production of pollutants from a micro reactor requires the use of chemical kinetics model which can highlight the contribution of combustion products with a high probability of occurrence. For this, the model of Jones and Lindstedt with a simplified chemical kinetics can be used. The simulated flames in stoichiometric and lean conditions $(\phi=1, \phi=0.9, \phi=0.7)$ are convex with a reaction zone extended resulting in a combustion temperature of about $2086 \mathrm{~K}, 2014 \mathrm{~K}$ and $1846 \mathrm{~K}$ respectively, depending on the richness of the mixture. The flue gas temperature at the outlet of the reactor remained almost constant and higher, respectively at $1850 \mathrm{~K}$, $1800 \mathrm{~K}$ and $1550 \mathrm{~K}$. This study is one of the few studies to test the simplified chemical kinetic model with four equations for the simulation of microflame compared to the widely used simplified one step equation. Pollutants such as carbon dioxide $\left(\mathrm{CO}_{2}\right)$, carbon monoxide (CO), and nitrogen monoxide (NO) were studied by varying the equivalent ratio. As for unburned fuel, the presence of carbon monoxide cannot be justified given the high level of the temperature of combustion products at the exit of the micro reactor, at least under the conditions studied. Carbon dioxide is not present in the flues gas. The presence of carbon monoxide is characteristic of an incomplete combustion; its presence should be resulted from the action of micro reactor walls where partial micro extinctions may occur. However, its presence is reduced and tends to disappear at the reactor outlet. The study of thermal NO was privileged because of the temperatures existing in the micro reactor being too high to favour the presence of fuel $\mathrm{NO}_{2}$ and prompt NO. The amounts of thermal NO approach a concentration of $0.8 \mathrm{ppm}$ in the three simulated cases. This value is much lower than the concentration produced by their macroscopic counterparts (1000-4000 ppm) and should potentially be less dangerous. The acceptable NO concentration is $1 \mathrm{ppm}$ in a breathable air. Since the thermal NO is favoured in lean conditions, the next challenge for the designers is to found a compromise between operating the MPG in these conditions and minimising the NO Production.

\section{Acknowledgments}

This work was partially supported by University of Quebec at Trois-Rivières by providing a Ph.D scholarship to O.T. Sosso Mayi.

\section{References}

D. C. Walther, J. Ahn, (2011), Advances and challenges in the development of power-generation systems at small scales, Progress in Energy and Combustion Science, vol. 37, pp 583-610

C. H. Marton, G. S. Haldeman, K. F. Jensen, (2011), Portable Thermoelectric Power Generator Based on a 
Microfabricated Silicon Combustor with Low Resistance to Flow, Industrial \& Engineering Chemistry Research, vol. 50, pp 8468-8475

A. L. Cohen, P. D. Ronney, U. Frodis, L. Sitzki, E. H. Meiburg, and S. Wussow, (2005), Microcombustor and combustionbased thermoelectric microgenerator," ed: Google Patents,

P. Aghalayam, P. Bui, D. Vlachos, (2010), The role of flamewall thermal interactions in flame stability and pollutant emissions, Advances in Chemical Propulsion: Science to Technology, p 435

J. Vican, B. F. Gajdeczko, F. L. Dryer, D. L. Milius, I. A. Aksay, and R. A. Yetter, (2002), Development of a microreactor as a thermal source for microelectromechanical systems power generation, pp 909-916

K. R. Smith, (1993), Fuel combustion, air pollution exposure, and health: the situation in developing countries, Annual Review of Energy and the Environment, vol. 18, pp 529. 566

S. Hill and L. Douglas Smoot, (2000), Modeling of nitrogen oxides formation and destruction in combustion systems, Progress in Energy and Combustion Science, vol. 26, pp 417-458

A. C. Fernandez-Pello, (2002), Micropower generation using combustion: Issues and approaches. Proceedings of the Combustion Institute, vol. 29, pp 883-899

J. Hedley, M. Pourkashanian, A. Williams, L. Yap, (1995), NO x Formation in Large-Scale Oxy-Fuel Flames. Combustion Science and Technology, vol. 108, pp 311-322

P. Schmitt, T. Poinsot, B. Schuermans, K. Geigle, (2007), Large-eddy simulation and experimental study of heat transfer, nitric oxide emissions and combustion instability in a swirled turbulent high-pressure burner. Journal of Fluid Mechanics, vol. 570, pp 17-46

P. A. Glaude, R. Fournet, R. Bounaceur, M. Molière, (2010) Adiabatic flame temperature from biofuels and fossil fuels and derived effect on NOx emissions, Fuel Processing Technology, vol. 91, pp. 229-235

H. Tsuji, A. K. Gupta, T. Hasegawa, M. Katsuki, K. Kishimoto, M. Morita, (2010), High temperature air combustion: from energy conservation to pollution reduction: CRC press

C. D. Hollowell, (2011). Combustion-generated indoor air pollution.

N. I. Kim, S. Kato, T. Kataoka, T. Yokomori, S. Maruyama, T. Fujimori, et al., (2005), Flame stabilization and emission of small Swiss-roll combustors as heaters. Combustion and Flame, vol. 141, pp 229-240

M. Efinger, J. Mauzey, V. McDonell, (2005), Characterization and reduction of pollutant emissions from a landfill and digester gas fired microturbine generator. pp 381-387

A. V. Boicea, G. Chicco, P. Mancarella, (2009), Optimal operation of a microturbine cluster with partial-load efficiency and emission characterization

M. Nascimento, E. Lora, and M. Rendon, (2007), Experimental Evaluation and Comparison of the Performance and Emissions of a Regenerative Gas Microturbine Using Biodiesel From Various Sources as Fuel.

COMSOL. Multiphysics, (2008), 4.2 a user guide, Stockholm, Sweden

F. A. Williams, (1965), Combustion Theory: the fundamental theory of chemical reacting flow systems: Addison-Wesley

D. G. Norton, D. G. Vlachos, (2003), Combustion characteristics and flame stability at the microscale: a CFD study of premixed methane/air mixtures, Chemical Engineering Science, vol. 58, pp 4871-4882

D. G. Norton, D. G. Vlachos, (2004), A CFD study of propane/air microflame stability. Combustion and Flame, vol. 138, pp 97-107
W. Jones and R. Lindstedt, (1988). Global reaction schemes for hydrocarbon combustion. Combustion and Flame, vol 73, pp. 233-249

J. Andersen, C. L. Rasmussen, T. Giselsson, P. Glarborg, (2009), Global combustion mechanisms for use in CFD modeling under oxy-fuel conditions. Energy \& Fuels, vol. 23, pp 1379-1389

S. Naha and S. K. Aggarwal, (2004), Fuel effects on NOx emissions in partially premixed flames. Combustion and flame, vol. 139, pp 90-105

C. Lee, C. Oh, J. Kim, (2004), Numerical and experimental investigations of the $\mathrm{NO}<\mathrm{sub}>\mathrm{x}</$ sub $>$ emission characteristics of $\mathrm{CH}<\mathrm{sub}>4</$ sub $>$-air coflow jet flames. Fuel, vol. 83, pp 2323-2334

S. Hill, L. Douglas Smoot, (2000), Modeling of nitrogen oxides formation and destruction in combustion systems. Progress in energy and combustion science, vol. 26, pp 417-458

E.-S. Cho, S. H. Chung, (2009), Numerical evaluation of NOx mechanisms in methane-air counterflow premixed flames. Journal of mechanical science and technology, vol. 23, pp 659-666

[28] G. P. Smith et al., (2010). Gri-Mech 3.0 http://www.me.berkeley.edu/gri_mech/

M. Nishioka, S. Nakagawa, Y. Ishikawa, T. Takeno, (1994), NO emission characteristics of methane-air double flame. Combustion and Flame, vol. 98, pp 127-138

W. Yang, W. Blasiak, (2005), Mathematical modelling of NO emissions from high-temperature air combustion with nitrous oxide mechanism," Fuel Processing Technology, vol. 86, pp 943-957

N. S. Kaisare, D. G. Vlachos, (2007), Optimal reactor dimensions for homogeneous combustion in small channels. Catalysis Today, vol. 120, pp 96-106

A. Gutkowski, (2013), Numerical Analysis of Effect of Ignition Methods on Flame Behavior During Passing Through a Sudden Contraction Near the Quenching Conditions. Applied Thermal Engineering

J. Li, S. K. Chou, W. M. Yang, Z. W. Li, (2009), A numerical study on premixed micro-combustion of CH4-air mixture: Effects of combustor size, geometry and boundary conditions on flame temperature. Chemical Engineering Journal, vol. 150, pp 213-222

K. Maruta, (2011). Micro and mesoscale combustion. Proceedings of the Combustion Institute, vol. 33, pp. 125150

O. Sosso Mayi, S. Kenfack, M. Ndamé, M. Obounou, J. T. Agbébavi, (2014), A numerical Simulation of Premixed Methane/Air Micro Flame: Effects of Simplified One Step Chemical Kinetic Mechanisms on the Flame Stability. Applied Thermal Engineering, vol. 73, pp 567-576

S. K. Chou, W. M. Yang, K. J. Chua, J. Li, and K. L. Zhang, (2011). Development of micro power generators - A review. Applied Energy, vol. 88, pp. 1-16

T. T. Leach, C. P. Cadou, G. S. Jackson, (2006), Effect of structural conduction and heat loss on combustion in micro-channels. Combustion Theory and Modelling, vol. 10 , pp 85-103

C. Law, C. Sung, (2000), Structure, aerodynamics, and geometry of premixed flamelets. Progress in Energy and Combustion Science, vol. 26, pp 459-505

J. A. Hoskins, (2003), Health effects due to indoor air pollution. Indoor and Built Environment, vol. 12, pp 427 433

D. G. Vlachos, L. D. Schmidt, and R. Aris, (1994), Products in methane combustion near surfaces. AIChE journal, vol. 40, pp 1018-1025

T. Takeno and M. Nishioka, (1993), Species conservation and emission indices for flames described by similarity solutions," Combustion and flame, vol. 92, pp 465-468 


\section{Nomenclature}

A Pre-exponential factor (consistent unit) $a, b c o n c e n t r a t i o n$ exponent

C Molar concentration, $\left(\mathrm{mol} / \mathrm{m}^{3}\right)$

CpSpecific heat, $(\mathrm{J} / \mathrm{kgK})$

$D_{j k}$ Multi component Maxwell-Stefan diffusivity, $\left(\mathrm{m}^{2} / \mathrm{s}\right)$

$\mathrm{E}_{\mathrm{a}} \quad$ Activation energy, (J/mol)

$H_{s r}$ Enthalpy of formation, $(\mathrm{J} / \mathrm{mol})$

$k$ Thermal conductivity, $(\mathrm{W} / \mathrm{mK})$

$\mathrm{k}^{\mathrm{f}}$ Reaction rate constant, $(1 / \mathrm{s})$

$M n$ Molar mass, $(\mathrm{kg} / \mathrm{mol})$

$n \quad$ Temperature exponent

$P \quad$ Pressure, $(\mathrm{Pa})$
$\mathrm{R}_{\mathrm{g}} \quad$ Universal gas constant, $(\mathrm{J} / \mathrm{mol} / \mathrm{K})$

$\mathrm{R}_{\mathrm{j}}$ Reaction rate of $\mathrm{j}$ species, $\left(\mathrm{mol} / \mathrm{m}^{3} / \mathrm{s}\right)$

$\mathrm{T}$ Temperature, $(\mathrm{K})$

$w_{i}$ Mass fraction

\section{Greek letters}

\author{
$\rho \quad$ Density, $\left(\mathrm{kg} / \mathrm{m}^{3}\right)$ \\ $\mu \quad$ Dynamic viscosity, (Pa.s) \\ $\phi \quad$ Equivalence ratio \\ $\delta_{r}$ Flame thickness, (m)
}

\section{Subscripts}

j Specie 